\title{
Upaya Peningkatan Kompetensi Kepala Sekolah sebagai Pemimpin Pembelajaran pada Program Sekolah Penggerak di Nganjuk
}

\author{
Efforts to Improve the Competence of Principals as Learning Leaders in Driving School \\ Programs in Nganjuk
}

\author{
Suesthi Rahayuningsih ${ }^{1}$, Achmad Rijanto ${ }^{2}$ \\ ${ }^{1}$ Program Studi Pendidikan Matematika, Fakultas Keguruan dan Ilmu Pendidikan, Universitas Islam \\ Majapahit, Indonesia \\ ${ }^{2}$ Program Studi Teknik Mesin, Fakultas Teknik, Universitas Islam Majapahit, Indonesia \\ e-mail: ${ }^{1}$ esthiachmad@gmail.com, ${ }^{2}$ rijanto1970@gmail.com
}

\begin{abstract}
Abstrak
Sejak tahun 2021 di kabupaten Nganjuk sudah banyak sekolah yang telah berpredikat sebagai sekolah penggerak. Permasalahan yang dihadapi oleh Kepala Sekolah PSP adalah masih kurangnya pengetahuan Kepala Sekolah tentang model kompetensi kepemimpinan pada sekolah penggerak. Tujuan dari kegiatan pengabdian masyarakat ini adalah meningkatkan kompetensi Kepala Sekolah program sekolah penggerak sebagai pemimpin pembelajaran dalam upaya untuk meningkatkan mutu sekolah. Metode yang digunakan dalam kegiatan ini adalah dalam bentuk lokakarya. Hasil yang dicapai setelah kegiatan ini adalah adanya pemahaman peningkatan pengetahuan Kepala Sekolah tentang model kompetensi sekolah yang terdiri dari empat kategori yaitu 1) pengembangan diri dan orang lain, 2) kepemimpinan pembelajaran, 3) kepemimpinan manajemen sekolah dan 4) kepemimpinan pengembangan sekolah. Dari keempat kategori model tersebut Kepala sekolah diberikan pendalaman materi peningkatan kompetensi sekolah, khususnya Kepala sekolah sebagai pemimpin pembelajaran di sekolah. Kategori kepemimpinan ini mempunyai 4 kompetensi yaitu a) memimpin upaya pengembangan lingkungan belajar yang berpusat pada murid, b) memimpin perencanaan dan pelaksanaan proses belajar yang berpusat pada murid, c) memimpin refleksi dan perbaikan kualitas proses belajar yang berpusat pada murid, dan d) melibatkan orang tua/wali murid sebagai pendamping dan sumber belajar di sekolah.
\end{abstract}

Kata kunci-kompetensi, kepala sekolah, pemimpin pembelajaran, program sekolah penggerak

\begin{abstract}
Since 2021 in Nganjuk district, there have been many schools that have been predicated as driving schools. The problem faced by the PSP Principal was that the Principal still lacks knowledge about the leadership competency model in the driving school. The purpose of this community service activity was to improve the competence of the principal of the driving school program as a learning leader in an effort to improve school quality. The method used in this activity was in the form of a workshop. The result achieved after this activity was an understanding of increasing the knowledge of the Principal about the school competency model which consists of four categories, namely 1) self and other people development, 2) learning leadership, 3) school management leadership and 4) school development leadership. Of the four categories of the model, the principal is given a deepening of the material for improving school competence, especially the principal as a learning leader in the school. This leadership category has 4 competencies, namely a) leading efforts to develop student-centered learning environments, b) leading the planning and implementation of student-centered learning processes, c) leading reflection and improvement of the quality of student-centered learning processes, and d) involving parents/guardians of students as companions and learning resources at school.
\end{abstract}

Keywords - competence, principal, learning leader, driving school program 


\section{PENDAHULUAN}

Keputusan Menteri Pendidikan dan Kebudayaan nomor 1177/M/2020, tahun 2020 (Mendikbud, 2020), tentang Program Sekolah Penggerak, mengatur tentang pedoman penyelenggaraan program sekolah penggerak. Sedangkan Program Sekolah Penggerak (PSP) sebagai model satuan pendidikan bermutu merupakan program Kementerian Pendidikan, Kebudayaan, Riset dan Teknologi, diperbarui disesuaikan kebutuhan pembaruan pembelajaran berdasarkan surat keputusan (SK) Menteri nomor 162/M/2021 (Mendikbudristek, 2021) (Mendikbudristek, 2021). Kepmendikbudristek nomor 162/M/2021, sebagai pengganti Kepmendikbud nomor 1177/M/2020. PSP adalah merupakan program Kemendikbudristek yang bertujuan untuk mewujudkan sekolah penggerak, yaitu sekolah yang mampu fokus mengembangkan hasil belajar siswa secara holistik untuk mewujudkan profil pelajar pancasila yang mencakup peningkatan kompetensi dan karakter yang diawali dengan peningkatan Sumber Daya Manusia (SDM) yang unggul dari Kepala Sekolah dan guru. Program ini merupakan kolaborasi antara Kemendikbudristek dengan pemerintah daerah diikuti oleh PAUD, SD, SMP, SMA dan SLB, baik negeri maupun swasta. Untuk mencapai tujuan yang telah dicanangkan dalam PSP, maka perlu adanya program untuk meningkatkan mutu sekolah sasaran PSP.

Kepala Sekolah sebagai seorang guru yang diberi tugas tambahan untuk memimpin sekolah, mempunyai tugas dan tanggungjawab yang besar untuk meningkatkan kualitas sekolah. Disamping sebagai pemimpin tertinggi di sekolah, dia juga melakukan tugas sebagai guru, yaitu melakukan kegiatan proses pembelajaran. Berdasarkan permendikbud nomor 6 tahun 2018 (Mendikbud, 2018), bahwa beban kerja Kepala Sekolah meliputi melaksanakan tugas pokok manajerial, pengembangan kewirausahaan dan melakukan supervisi kepada guru dan tenaga kependidikan dalam upaya untuk meningkatan mutu sekolah. Salah satu upaya Kepala sekolah untuk meningkatkan mutu sekolah adalah mengikuti Program Sekolah Penggerak (PSP) yang diselenggarakan oleh Kementrian Pendidikan, Kebudayaan, Riset dan Teknologi (Kemendikbudristek).

Berdasarkan hasil analisis situasi, bahwa di kabupaten Nganjuk sejak tahun 2021, sudah ada beberapa sekolah pada jenjang Pendidikan Anak Usia Dini (PAUD), jenjang pendidikan dasar dan menengah, baik negeri maupun swasta yang telah memenuhi predikat sebagai sekolah penggerak, sesuai Keputusan Direktur jenderal Guru dan Tenaga Kependidikan No. 2237/B.B2/KP.04.00/2021 Kemendikbudristek (Dirjen GTK, 2021), tentang Penetapan Kepala Sekolah Pelaksana Program Sekolah Penggerak. Untuk kabupaten Nganjuk jenjang PAUD antara lain TK Pertiwi 2 Ngadipiro, TK Pertiwi Gemenggeng, TK Al Fatah Margopatut, TK Dharma Wanita Ngrami, TK Mutiara hati Ploso dan lain-lai. Untuk jenjang pendidikan dasar antara lain SDN 1 Plosoharjo, SDN 2 Gemenggeng, SDN1 Banaranwetan, SDIT Al Haromain, SDIT Baitul Izzah dan lain-lain. Sedangkan untuk pendidikan menengah antara lain SMAN 1 Sukomoro, SMAN 1 Patianrowo, SMAN 3 Nganjuk, SMPN 1 Prambon, SMP Islam Batul Izzah Nganjuk dan lain-lain. Dari analisis situasi yang telah dilakukan PAUD dan sekolah penggerak tersebut, permasalahan yang dihadapi masih kurangnya pengetahuan Kepala Sekolah penggerak tentang model kompetensi kepemimpinan sekolah penggerak, sehingga untuk pencapaian tujuan dari sekolah penggerak akan sulit dicapai manakala Kepala Sekolah tidak memiliki pengetahuan tersebut. Berdasarkan permasalahan tersebut perlu adanya upaya untuk meningkatkan pengetahuan Kepala Sekolah Penggerak tentang model kompetensi kepemimpinan sekolah penggerak. Kegiatan PSP diawali dengan peningkatan mutu sumber daya manusia di sekolah yaitu Kepala Sekolah dan guru.

Peningkatan mutu SDM dapat dilakukan dengan memberikan pengetahuan yang belum dimiliki oleh SDM tersebut, melalui pendidikan maupun pendidikan dan pelatihan. Berdasarkan Peraturan Direktur jenderal Guru dan Tenaga Kependidikan No. 6565/B/GT/2020 Kemendikbudristek (Dirjen GTK, 2020), tentang Model Kompetensi dalam Pengembangan Profesi Guru menyatakan, bahwa guru harus mengembangkan keprofesionalannya paling sedikit melalui pendidikan dan/ atau pendidikan dan pelatihan. Pendidikan merupakan pendidikan profesi, sedangkan pendidikan dan pelatihan merupakan pengembangan kompetensi dalam

Upaya Peningkatan Kompetensi Kepala Sekolah sebagai Pemimpin Pembelajaran pada Program Sekolah Penggerak di Nganjuk (Suesthi Rahayuningsih ${ }^{1}$, Achmad Rijanto ${ }^{2}$ ) 
melaksanakan tugas. Pendidikan profesi maupun pendidikan dan pelatihan harus menggunakan model kompetensi.

Berdasarkan kegiatan pengabdian masyarakat sebelumnya menurut (Suparno, 2018), bahwa kegiatan lokakarya Kepala sekolah dan staff Sekolah Menengah Kejuruan (SMK) Asosiasi Sekolah Jesuit Indonesia (ASJI) tentang pengembangan Paradigma Pedagogi Ignation (PPI) dapat meningkatkan pemahaman peserta mengenai isi pokok dan semangat serta Rencana Pelaksanaan Pembelajaran khas PP. Sedangkan menurut (Nursyifa \& Nurzaman, 2019), pembinaan Kepala Sekolah dalam meningkatkan mutu pendidikan dalam bentuk workshop, dapat meningkatkan pemahaman Kepala Sekolah tentang fungsi dan tugas pokoknya dalam mengelola sekolah. Menurut (Rijanto \& Rahayuningsih, 2021), bahwa upaya peningkatan SDM melalui pelatihan dan pendampingan yang telah dilakukan pada pengusaha mikro kerupuk samiler di Kabupaten Mojokerto, menunjukkan adanya peningkatan pengetahuan sebesar $40 \%$ dan peningkatan ketrampilan sebesar $55 \%$ untuk perawatan mesin parut berbahan bakar gas. Selain itu, kegiatan bagi siswa terkait dengan pelatihan menulis deskripsi dengan menggunakan media gambar dapat meningkatkan pemahaman peserta didik dalam meningkatkan karakter religius, jujur, disiplin, demokratis, rasa ingin tahu, komunikatif, peduli sosial dan tanggunng jawab (Prasetyo Yuli Kurniawan, 2021). Berdasarkan pengabdian yang lain menurut (Permana \& Muhtadi, 2021), bahwa pendampingan kepada Kepala Sekolah dalam rekrutmen guru dapat memperoleh guru yang lebih berkualitas, karena mulai dari perencanaan, proses pelaksanaan sampai dengan penetapan guru yang diterima mendapat pendampingan.

Gaya kepemimpinan sekolah dapat mewarnai keberlangsungan sekolah, terutama dalam meningkatkan mutu pendidikan di sekolah. Menurut (Minsih et al., 2019), bahwa peran kepemimpinan Kepala Sekolah di Madrasah Ibtidaiyah Muhammadiyah (MIM) Program Khusus Kartasura, dilaksanakan secara demokratis-monarki, keputusan diambil secara bersamasama dan kepemimpinan kepala sekolah sebagai pendidik, manajer, administrator, supervisor, pemimpin, innovator serta motivator dapat sebagai contoh dalam menjalankan tugas di sekolah. Menurut (Nasution \& Ichsan, 2020), bahwa gaya kepemimpinan Kepala Sekolah berpengaruh positif dan signikan terhadap kinerja guru pada SMP Yayasan Perguruan Letjen S. Parman Medan. Hal ini ditunjukkan dengan hasil pengujian koefisien diterminasi sebesar 0,569, yang berarti 56,9 \% gaya kepemimpinan mempengaruhi kinerja guru. Sedangkan menurut (Ideswal et al., 2020), gaya kepemimpinan Kepala Sekolah terhadap kinerja guru SDN di kota Payakumbuh hanya sebesar 8,6 \%. Upaya yang telah dilakukan untuk meningkatkan kompetensi Kepala Sekolah adalah mengadakan lokakarya Kepala Sekolah PSP sebagai bekal Kepala Sekolah, khususnya tentang kepemimpinan sekolah penggerak. Peserta kegiatan lokarya tersebut antara lain yaitu SDN 1 Mojoagung, SDN 1 Plosoharjo, SDN 2 Gemenggeng, SMPN 1 Prambon, SMP Islam Baitul Izzah Nganjuk, SMPN 2 Lengkong, SMAN 1 Prambon, SMAN Kertosono, SMAN 3 Nganjuk dan lain-lain. Di samping Kepala Sekolah, hadir pula beberapa pengawas dari Dinas Pendidikan kabupaten Nganjuk.

\section{METODE DAN PELAKSANAAN}

Pelaksanaan kegiatan pengabdian ini dilaksanakan di Nganjuk pada bulan November 2021. Metode yang digunakan adalah dalam bentuk lokakarya. Kegiatan ini diikuti oleh peserta sebanyak 18 orang, terdiri dari unsur Kepala SD, SMP dan SMA, baik negeri maupun swasta serta unsur pengawas dari Dinas Pendidikan kabupaten Nganjuk. Peserta dari jenjang SD diikuti sebanyak 3 SD, yaitu SDN 1 Mojoagung, SDN 1 Plosoharjo dan SDN 2 Gemenggeng. Peserta dari jenjang SMP diikuti sebanyak 4 SMP, yaitu SMPN 1 Patianrowo, SMPN 1 Prambon, SMP Islam Batul Izzah Nganjuk dan SMPN 2 Lengkon. Sedangkan dari jenjang SMA dikuti sebanyak 5 SMA, yaitu SMAN 1 Sukomoro, SMAN 1 Patianrowo, SMAN 3 Nganjuk, SMAN 1 Prambon dan SMAN 1 Kertosono. Dan selebihnya sebanyak 6 orang unsur pengawas dari Dinas Pendidikan Kabupaten Nganjuk. 
Kegiatan lokakarya ini dilaksanakan di hotel Istana Nganjuk. Pada kegiatan lokakarya ini sebagai nara sumber utama adalah Pelatih Ahli (PA), Suesthi Rahayuningsih, S.Si., M.Pd dari Universitas Islam Majapahit. Materi yang disampaikan dalam kegiatan ini adalah model kompetensi kepemimpinan sekolah meliputi eksplorasi konsep, ruang kolaborasi, refleksi terbimbing, demonstrasi kontekstual dan elaborasi pemahaman. Pelaksanaan lokakarya ini dilaksanakan dalam bentuk metode ceramah, diskusi dan simulasi praktik. Dengan harapan para peserta dapat lebih mudah untuk menerima materi yang telah disampaikan sekaligus mempraktikkannya dalam bentuk simulasi. Diagram alur pelaksanaan kegiatan pengabdian ini dapat dilihat pada Gambar 1.

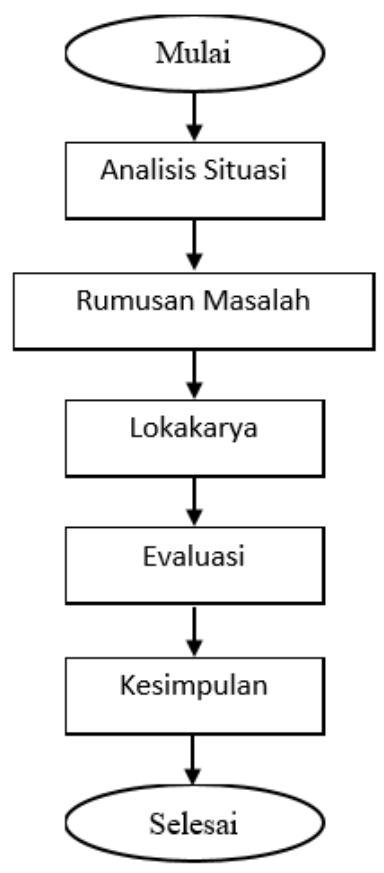

Gambar 1. Diagram alur pengabdian

\section{HASIL DAN PEMBAHASAN}

Model kompetensi kepemimpinan sekolah merupakan representasi dari kepemimpinan pendidikan yang terintegrasi. Model kepemimpinan ini perlu ada di sekolah, karena sebagai dasar dari sistem pengelolaan sekolah dan sebagai acuan bagi sejumlah strategi transformasi pendidikan, Model kompetensi kepemimpinan sekolah terdiri dari empat kategori, yaitu kategori yaitu 1) pengembangan diri dan orang lain 2) kepemimpinan pembelajaran 3) kepemimpinan manajemen sekolah dan 4) kepemimpinan pengembangan sekolah.

Model kompetensi kepemimpinan sekolah dikhususkan pada kategori kepemimpinan pembelajaran. Kategori kepemimpinan ini mempunyai 4 kompetensi yaitu 1) memimpin upaya pengembangan lingkungan belajar yang berpusat pada murid, 2) memimpin perencanaan dan pelaksanaan proses belajar yang berpusat pada murid, 3) memimpin refleksi dan perbaikan kualitas proses belajar yang berpusat pada murid, dan 4) melibatkan orang tua/wali murid sebagai pendamping dan sumber belajar di sekolah.

Untuk mencapai kompetensi yang pertama, memimpin upaya pengembangan lingkungan belajar yang berpusat pada murid ada empat indikator yang harus dipenuhi yaitu a) mengembangkan dan merawat lingkungan sekolah yang nyaman dan aman bagi warg a sekolah, b) mengembangkan komunikasi dan interaksi warga sekolah yang saling percaya dan peduli, c) memfasilitasi masukan dan aspirasi murid dalam penyusunan kebijakan pegembangan 
lingkungan belajar dan pelaksanaan praktik belajar, dan d) memastikan guru melibatkan murid dalam membangun lingkungan belajar yang kondusif.

Pada Gambar 2 menunjukkan narasumber lokakarya sedang menyampaikan materi kepada peserta lokakarya, yaitu Kepala Sekolah dan Pengawas Sekolah dari Dinas Pendidikan di Kabupaten Nganjuk.

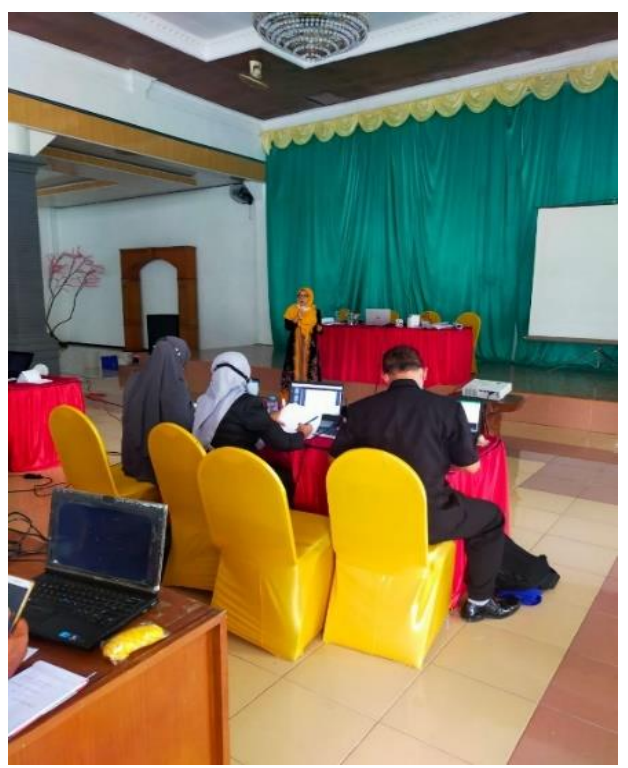

Gambar 2. Narasumber menyampaikan materi kepada peserta

Untuk mencapai kompetensi yang kedua, memimpin perencanaan dan pelaksanaan proses belajar yang berpusat pada murid, ada empat indikator yang harus diraih yaitu a) memimpin pertemuan guru untuk merencanakan proses belajar yang berpusat pada murid, b) memberi umpan balik terhadap perencanaan dan pelaksanaan proses belajar sebagai dasar bagi guru melakukan perbaikan, c) menunjukkan praktik pembelajaran yang berpusat pada murid sebagai teladan bagi guru, dan d) menyediakan dukungan agar guru fokus dalam melaksanakan proses belajar yang berpusat pada murid.

Peserta lokakarya melakukan diskusi tentang materi yang telah disampaikan oleh nara sumber dapat dilihat pada Gambar 3.

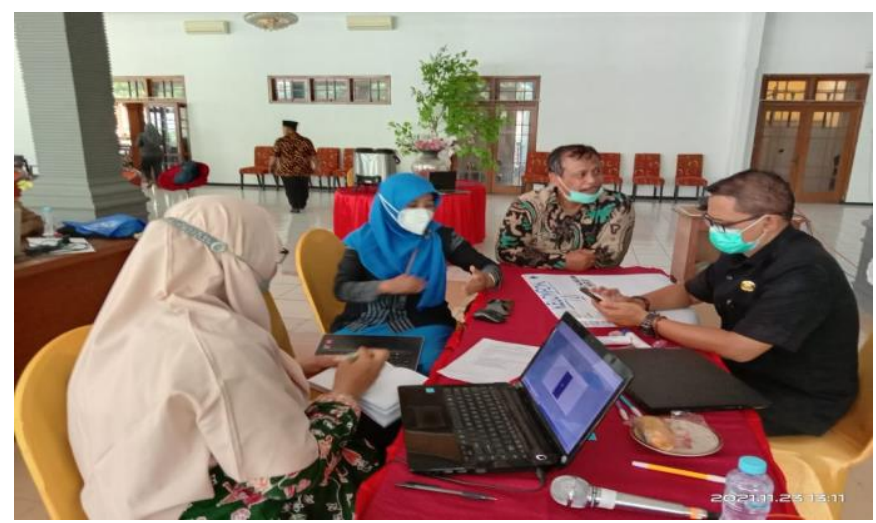

Gambar 3. Peserta berdiskusi tentang materi lokakarya

Untuk mencapai kompetensi yang ketiga, memimpin refleksi dan perbaikan kualitas proses belajar yang berpusat pada murid, ada empat indikator yang harus diraih yaitu a) mengoordinasi pengumpulan dan pengolahan data terkait proses dan hasil belajar murid, b) mengoordinasi evaluasi praktik pembelajaran berdasarkan data terkait proses dan hasil belajar murid, c) memimpin pertemuan refleksi secara berkala untuk perbaikan kualitas proses belajar, 
dan d) membimbing guru untuk melakukan perbaikan kualitas proses belajar berdasarkan hasil dari refleksi.

Untuk mencapai kompetensi yang keempat, melibatkan orang tua/wali murid sebagai pendamping dan sumber belajar di sekolah, ada enam indikator yang harus diraih yaitu a) mendukung guru untuk memahami kebutuhan dan karakteristik orang tua/wali murid, b) menginisiasi komunikasi dan interaksi dengan orang tua/wali murid, c) menyediakan dukungan kepada guru agar dapat berkomunikasi dan berinteraksi dengan orang tua/wali murid, d) menyediakan kesempatan terbuka bagi orang tua/wali murid untuk menyampaikan pendapat, e) menyediakan kesempatan bagi orang tua/wali murid untuk berperan sebagai pendamping dan sumber belajar dan f) mendorong orang tua/wali murid untuk menggunakan kesempatan sebagai pendamping dan sumber belajar.

Jenjang kompetensi kepemimpinan dilihat dari dua unsur yaitu praktik kepemimpinan: derajat jangkauan kepemimpinan dan orientasi kepemimpinan: derajat dampak praktik kepemimpinan. Kelompok jenjang kompetensi kepemimpinan dapat dilihat pada Tabel 1.

Tabel 1. Jenjang kompetensi kepemimpinan

\begin{tabular}{|c|c|c|c|}
\hline Berkembang & Layak & Cakap & Mahir \\
\hline $\begin{array}{l}\text { Praktik kepemimpina } n \\
\text { pada lingkup tim/ } \\
\text { kegiatan. }\end{array}$ & $\begin{array}{l}\text { Melakukan praktik } \\
\text { kepemimpinan sekolah } \\
\text { melalui manajemen } \\
\text { yang baik dan } \\
\text { berorientasi pada murid. }\end{array}$ & $\begin{array}{l}\text { Melakukan praktik } \\
\text { kepemimpinan dengan } \\
\text { memfasilitasi guru } \\
\text { untuk tumbuh, } \\
\text { berkembang, dan } \\
\text { berbagi praktik baik } \\
\text { yang berorientasi pada } \\
\text { murid. }\end{array}$ & $\begin{array}{l}\text { Membangun budaya } \\
\text { kepemimpinan di } \\
\text { kalangan guru melalui } \\
\text { manajemen yang baik } \\
\text { dan berorientasi pada } \\
\text { murid. }\end{array}$ \\
\hline $\begin{array}{l}\text { Orientasi operasional } \\
\text { kegiatan: memastikan } \\
\text { kegiatan berjalan } \\
\text { lancar. }\end{array}$ & $\begin{array}{l}\text { Orientasi operasional } \\
\text { sekolah: memastikan } \\
\text { kegiatan dan } \\
\text { operasional harian } \\
\text { sekolah berjalan efektif. }\end{array}$ & $\begin{array}{l}\text { Orientasi relasional } \\
\text { strategis: merawat relasi } \\
\text { dan memantau } \\
\text { kemajuan untuk } \\
\text { pencapaian sasaran } \\
\text { strategis sekolah. }\end{array}$ & $\begin{array}{l}\text { Orientasi sistem dan } \\
\text { mekanisme: } \\
\text { membangun kolaborasi } \\
\text { dan program melibatkan } \\
\text { komunitas yang } \\
\text { membuat sekolah } \\
\text { berdampak luas. }\end{array}$ \\
\hline
\end{tabular}

Peserta lokakarya dan narasumber setelah acara selesai melakukan foto bersama, dapat dilihat pada Gambar 4.

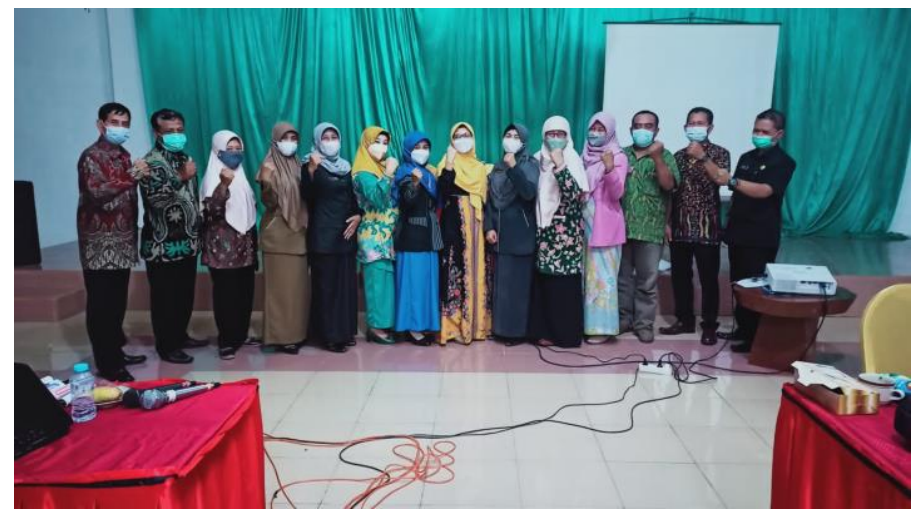

Gambar 4. Peserta dan narasumber lokakarya

\section{KESIMPULAN}

Setelah mengikuti kegiatan ini Kepala Sekolah PSP di kabupaten Nganjuk telah memahami tentang model kompetensi sekolah yang terdiri dari empat kategori yaitu 1) pengembangan diri dan orang lain 2) kepemimpinan pembelajaran 3) kepemimpinan 
manajemen sekolah dan 4) kepemimpinan pengembangan sekolah. Dari keempat kategori model tersebut Kepala Sekolah diberikan pendalaman materi peningkatan kompetensi sekolah, khususnya Kepala Sekolah sebagai pemimpin pembelajaran di sekolah, sehingga Kepala Sekolah mengetahui lebih mendalam tentang empat kompetensi kategori kepemimpinan ini, yaitu a) memimpin upaya pengembangan lingkungan belajar yang berpusat pada murid, b) memimpin perencanaan dan pelaksanaan proses belajar yang berpusat pada murid, c) memimpin refleksi dan perbaikan kualitas proses belajar yang berpusat pada murid, dan d) melibatkan orang tua/wali murid sebagai pendamping dan sumber belajar di sekolah.

Saran yang dapat disampaikan adalah bahwa untuk lebih meningkatkan pengetahuan kepala sekolah tentang peningkatan kompetensi Kepala Sekolah sebagai pemimpin pembelajaran di sekolah lebih maksimal, maka perlu adanya penambahan waktu pelaksanaan yang cukup, agar dapat dilaksanakan refleksi yang lebih baik kepada peserta lokakarya.

\section{DAFTAR PUSTAKA}

Dirjen GTK. (2020). Model Kompetensi dalam Pengembangan Profesi Guru. Peraturan Direktur Jenderal Guru Dan Tenaga Kependidikan Nomor 6565/B/GT/2020.

Dirjen GTK. (2021). Penetapan Kepala Sekolah Pelaksana Program sekolah Penggerak. Keputusan Direktur Jenderal Guru Dan Tenaga Kependidikan Nomor 2237/B.B2/KP.04.00/2021.

Ideswal, I., Yahya, Y., \& Alkadri, H. (2020). Kontribusi Iklim Sekolah dan Kepemimpinan Kepala Sekolah Terhadap Kinerja Guru Sekolah Dasar. Jurnal Basicedu, 4(2), 460-466.

Mendikbud. (2018). Penugasan Guru Sebagai Kepala Sekolah. Peraturan Menteri Pendidikan Dan Kebudayaan (Permendikbud) Nomor 6 Tahun 2018.

Mendikbud. (2020). Program Sekolah Penggerak. Keputusan Menteri Pendidikan Dan Kebudayaan Nomor 1177/M/2020.

Mendikbudristek. (2021). Program Sekolah Penggerak. Keputusan Menteri Pendidikan, Kebudayaan, Riset Dan Teknologi (Kepmendikbudristek) Nomor 162/M/2021.

Minsih, M., Rusnilawati, R., \& Mujahid, I. (2019). Kepemimpinan Kepala Sekolah Dalam Membangun Sekolah Berkualitas Di Sekolah Dasar. Jurnal Profesi Pendidikan Dasar, 1(1), 29-40. https://doi.org/10.23917/ppd.v1i1.8467

Nasution, L., \& Ichsan, R. N. (2020). Gaya Kepemimpinan Kepala Sekolah Terhadap Kinerja Guru. Jurnal Penelitian Pendidikan Sosial Humaniora, 5(2).

Nursyifa, A., \& Nurzaman, E. (2019). Pembinaan Kepala Sekolah Dalam Upaya Meningkatkan Mutu Pendidikan. In Journal of Community Services in Humanities and Social Sciences (Vol. 1, Issue 1).

Permana, A. ,I., \& Muhtadi, T. ,Y. (2021). Pendampingan Kepala Sekolah Pada Kegiatan Rekrutmen Guru Sebagai Syarat Pendirian Sekolah Menengah Pertama (SMP) Citra Insan Mulia. JURPIKAT (Jurnal Pengabdian Kepada Masyarakat), 2(1), 117-125. https://doi.org/10.37339/jurpikat.v2i1.491

Prasetyo Yuli Kurniawan, dkk. (2021). Pelatihan Menulis Deskripsi dengan menggunakan Media Gambar untuk Menumbuhkan Nilai-Nilai Karakter. JAMU: Jurnal Abdi Masyarakat, 1(02), 37-43.

Rijanto, A., \& Rahayuningsih, S. (2021). Pelatihan dan Pendampingan Perawatan Alat Produksi Pada Usaha Mikro Kerupuk Samiler. JAMU: Jurnal Abdi Masyarakat UMUS, 1(02), 1723.

Suparno, P. (2018). Lokakarya Kepala Sekolah dan Staf SMK ASJI Tentang PPI. ABDIMAS ALTRUIS: Jurnal Pengabdian Kepada Masyarakat, 01(01), 31-35. https://doi.org/10.24071/altruis.2018.010106 